\title{
Reflections on the Formulary System from 1997 to the Present
}

\author{
Steven G. Avey, MS, RPh, FAMCP
}

T he 1997 JMCP article "Managing the Pharmacy Benefit: The Formulary System" was inspiring. It was written when the formulary development process was young, yet the author looked forward, postulating future ways in which formularies could be used within the managed care pharmacy system. Few health care experts of that day could have foreseen the changes that would occur in the 20-year span since JMCP published this article. Few prognosticators could have predicted the incredible rise in

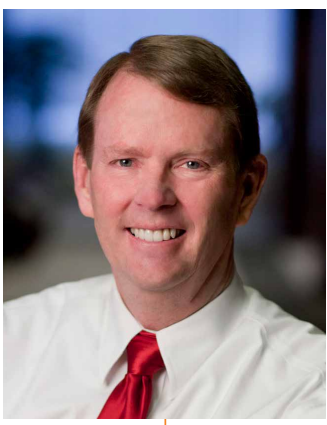
its subtype, and potentially the genetic mutations present. With $\$ 15,000-\$ 75,000$ monthly costs for these medications, some managed care plans are requiring documentation of the diagnosis and genetic markers. This has put a substantial burden on prescribers and their practices that has led to criticism and requests for legislative relief. Those were not present in 1997.

The article stated that the average cost of a prescription drug in 1997 was $\$ 27.40$. In 2019, the average cost of a prescription drug using a the development and use of specialty pharmaceuticals or the major shift in focus for pharmacy and therapeutics (P\&T) committee agendas over the past decade.

Formularies were only a decade old in 1997, and the JMCP article discussed their acceptance in the marketplace and highlighted some of the criticism aimed at them. Today, formularies are well established and recognized as the basis for ensuring that clinically and financially appropriate therapies are being used. While many employers were considering adding a formulary to their management programs in 1997, this has become standard practice today. Employers have become educated about the different types of formularies to use in their populations and consistently ask intelligent questions about their effect financially and from a member disruption perspective.

Criticism today about the use of formularies is not pointed at their use but centers around the substantial escalation of prior authorizations (PA) that prescribers must respond to in their practice settings. Because of current formulary practice, most high-cost medications carry a PA on them to acquire coverage, and the amount of information required in those PAs has substantially increased. With the complexities of specialty pharmaceuticals and their indications, formulary committees are demanding to know what disease is being treated,

discounted average wholesale price is $\$ 211.10$, an almost 8-fold increase, according to an analysis using MedImpact Health Systems paid prescription claims data (unpublished data, MedImpact analysis, November 29, 2019). Specialty pharmaceuticals, which had not been delineated in 1997, represent approximately half of the total prescription spend. According to the same analysis by MedImpact, the average cost of a core specialty prescription (defined as those medications within the most prominent specialty classes, including oncology, autoimmune, and multiple sclerosis, which are responsible for the majority of specialty spend) in 2019 is $\$ 6,822.78$ (unpublished data, MedImpact analysis, November 29, 2019). This dramatic rise in the average cost of a prescription supports the importance of an effective formulary system.

In 1997, the emphasis of formularies was on drug efficacy and how the formulary system helped determine its validity. It is no wonder that the emphasis of P\&T committees today is searching for clinical efficacy and value, which requires formulary teams to focus on the cost of the pharmaceutical and on reduction of other medical resources through the use of pharmacoeconomic evaluations. Organizations such as the Institute for Clinical and Economic Review is having a greater influence on P\&T committees as they publish their evaluations on new therapies using quality-adjusted life-years gained compared with existing medications.

The 1997 article provided some excellent insight into how medications were evaluated by P\&T committees at the time. 
The information that reviewers had available for new medications was limited compared with information available today. However, starting in 2000, the AMCP Format for Formulary Submissions changed the world of drug evaluation. ${ }^{2}$ For the first time, all the information that a P\&T committee needed to request from a manufacturer was systematically placed in the Format document to standardize the evaluation process across the country. Since 2000, this document and process have had an important effect on P\&T committees, and AMCP has rigorously reevaluated and updated the Format 4 times to ensure that it stays relevant in current practice.

Outcomes-based contracting was conceived of over 20 years ago, but the 1997 article makes it clear this tool was more hypothetical than practical at that time. Today, outcomesbased contracting is fairly commonplace, although the financial relief promised has not been well established to date. However, financial relief is not the only goal of outcomes-based analyses. Some managed care organizations are using real-world evidence studies to assist them in a better understanding of differences in important outcomes among competing therapies. This evidence is being used by some managed care organizations to guide future formulary decisions. If a specific drug therapy has provided higher adherence and persistency rates or improved disease-state outcomes, compared with competing drugs, the plan can use that data to make more informed formulary decisions at future $P \& T$ committee meetings.

Since the human genome sequence was identified in April 2003, pharmaceutical companies have poured millions of dollars into research to develop new drugs with far more targeted populations and therapies for orphan conditions that were previously untreatable. With that explosive development has come much higher costs for these complex medications, including new gene therapies. Even greater education and training have been required for formulary reviewers, since they must stay abreast of all the new drug technology that has provided hope to many patients with serious diseases.

Although not imagined in 1997, current P\&T committees are struggling to determine what to do with new multimilliondollar gene therapies. P\&T committees today are responsible for guiding managed care plan administrators as they make difficult decisions on affordability, benefit structure, and the efficacy of these therapies over a patient's lifetime. These are challenges that managed care plans in 1997 could likely not have imagined.

The 1997 article gave excellent information about the relatively new managed care tool called a drug formulary. It is impressive to consider the work many managed care organizations did to initiate and develop formulary programs and then adapt them over the past 22 years. Incredible changes have occurred in the marketplace with new high-tech treatments being made available that carry huge costs and favorable outcomes. Colleges of pharmacy and organizations such as AMCP have been up to the task of further developing highly educated reviewers and committee members to meet the challenges they must face. Overall, it appears that these committees are meeting the huge challenges they face and continue to make available life-altering and at times life-saving treatments to managed care members across our country in a financially responsible manner.

\section{Authors}

STEVEN G. AVEY, MS, RPh, FAMCP, AMCP Foundation, Alexandria, Virginia.

AUTHOR CORRESPONDENCE: Steven G. Avey, MS, RPh, FAMCP. E-mail: aveyrph@gmail.com.

\section{DISCLOSURES}

No funding was received for the writing of this reflection. Avey is a member of the AMCP Foundation and has recently retired from MedImpact Health Systems, where he served as Vice President of Specialty Clinical Solutions.

\section{REFERENCES}

1. Goldberg, R. Managing the pharmacy benefit: the formulary system. J Manag Care Pharm. 1997;3(5):565-73. Available at: https://www.jmcp.org/ doi/abs/10.18553/jmcp.1997.3.5.565

2. Academy of Managed Care Pharmacy. The AMCP Format for Formulary Submissions. Version 4.0. April 2016. Available at: http://www.amcp.org/sites/ default/files/2019-03/AMCP-Format-V4.pdf. Accessed February 17, 2020. 